\title{
Revisitando el mal y la culpa en el contexto de la sociedad plural y a la luz de la misericordia
}

\author{
Prof. Dr. Roberto Noriega Fernández \\ Estudio Teológico Agustiniano de Valladolid
}

Recibido: 1 de septiembre 2021

Aceptado: 5 de noviembre 2021

Resumen: La comprensión actual de la realidad del mal y de la culpabilidad está recibiendo nuevas y sugerentes aproximaciones desde las ciencias experimentales o el magisterio eclesial y con motivo de la pandemia del COVID-19. Merece la pena revisitar el tema para analizar dichas novedades y su posible influencia en la reflexión teológica.

Después de hacer una lectura de los datos que sugieren una nueva etapa en una deliberación sobre el mal objetivo y la responsabilidad subjetiva de carácter interdisciplinar, se apuntan algunas temáticas en las que la teología queda afectada buscando el espacio que le corresponde en el ágora de las sociedades plurales.

Palabras clave: Culpabilidad, mal, misericordia, pluralismo

Abstract: The current understanding of the reality of evil and guilt is receiving new and suggestive approaches from the experimental sciences or the ecclesial magisterium and on the COVID-19 pandemic. It is worth revisiting the subject to analyze these novelties and their possible influence on theological reflection. 
After making a reading of the data that suggest a new stage in a deliberation on the objective evil and subjective responsability of an interdisciplinary methods, some themes are pointed out in which theology is affected looking for the space that corresponds to it in the agora of plural societies.

Keywords: Evil, guilt, mercy, pluralism

\section{Introducción}

Algunas orientaciones del papa Francisco en la Constitución apostólica Veritatis gaudium ${ }^{1}$, sugieren acompañar los procesos culturales y sociales, especialmente las transiciones difíciles que generan conflictos. Se trata de hacerse cargo de dichos conflictos, conocerlos, iluminarlos, si fuera posible elaborando herramientas intelectuales útiles para el anuncio del Evangelio.

Sin duda, que entre los temas conflictivos y de difícil encaje en las sociedades plurales está la explicación de la realidad del mal; su origen, su gestión y su relación con la responsabilidad y culpabilidad humanas².

El objetivo de este texto será revisitar dichas cuestiones buscando las voces nuevas para nuestra época $(P P ., 47)$, señalando las novedades que incorpora el escenario actual: a) destacando la situación de la catástrofe del COVID; b) el desarrollo de las ciencias neuro-psicológicas; c) los últimos documentos eclesiales. En un segundo momento se señalará: a) cómo puede afectar a la teología; b) a la antropología; c) y cómo dialogar con lo secular para enriquecerse mutuamente.

En este identificar y asumir los conflictos, para ampliar desde dentro la reflexión de la Tradición, se puede asumir la afirmación de la European Society for Catholic Theology cuando postula que: "The most specifically European contribution to the global theological discussion of today: namely, Europe's tradition of dealing with rational philosophical approaches

${ }^{1}$ Cfr. Francisco, Constitución apostólica Veritatis gaudium, sobre las universidades y facultades eclesiásticas, Roma 2018.

${ }^{2}$ Tobeña indica del siguiente modo: "los perfiles perversos de la condición humana y la responsabilidad que en ellas se encierra”. ToBEÑA, AdOLF, Neurología de la maldad. Mentes predadoras y perversas, Plataforma editorial, Barcelona 2017, preámbulo. 
to theological questions, the different religious denominations and secular world views" 3 .

\section{1.- Nuevos actores en el escenario}

Antes de marcar los nuevos actores en un escenario enorme en el que se representa la inmensa tragedia del mal, se pueden identificar diferentes elementos en la tramoya:

- Aunque algunos autores han señalado una cierta penuria teológica, ésta coexiste con el interés secular y científico, a juzgar por los estudios académicos ${ }^{4}$ sobre el mal o sus consecuencias: la pobreza (Cortina $\left.^{5}\right)$, la insensibilidad inhumana $\left(\right.$ Marina $\left.^{6}\right)$.... tratando de medir su intensidad, especialmente desde la sociología de los valores?

- Igualmente existe un renovado atractivo 'popular' por la realidad del mal, tomando como muestra la prensa escrita ${ }^{8}$, documentales y programas de TV, y películas de cine'.

- La culpabilidad se hace presente pero no de modo explícito, se diría que por razones de estética o higiénicas. Lo que permite una

3 Prüller-Jagenteufel, Gunter - Kruip, Gerhard, “European theology” (editorial): ET Studies. Journal of the European Society for Catholic Theology 11/1 (2020) vi.

${ }^{4}$ Una primera idea es recordar que la problemática del mal no solo no ha desaparecido, sino que tiene su espacio público en la investigación (maldad casi 86000 entradas en Google scholar, 169000 wickedness) (Julio del 2021).

${ }^{5}$ Cfr. Cortina Ors, Adela, Aporofobia, el rechazo al pobre. Un desafío para la democracia, Paidós, Barcelona 2017.

${ }^{6}$ Cfr. Marina, José Antonio, Biografía de la inhumanidad. Historia de la crueldad, la sinrazón y la insensibilidad humanas, Ariel, Barcelona 2021.

${ }^{7}$ Cfr. GonzÁlez-Anleo, Juan Maria - López-Ruiz, José A., Jóvenes españoles entre dos siglos 1984-2017, Fundación SM, Madrid 2017; FundACIÓn BBVA, Estudio Internacional de Valores, Septiembre de 2019, Primera parte https://www.fbbva.es/wp-content/uploads/2019/09/Presentacion_Estudio_Valores_2019.pdf (marzo del 2020)

${ }^{8}$ Cfr. Carrascal, José María, El mal existe: Diario ABC (20 de diciembre del 2018) 3; Albiac, Gabriel, La maldad: Diario ABC (4 de enero del 2018)10.

${ }^{9} \mathrm{El}$ mal de algún modo atrae, es un campo prohibido que genera un concepto fascinante y atractivo que sigue generando muchas preguntas. Sirva como ejemplo, una serie de documentales del periodista Jon Sistiaga enmarcados en un programa titulado significativamente Tabú. Algunos capítulos son los siguientes: La maldad: ¿De qué está hecho un malo?; La semilla del mal; Más líbranos del mal; ¿La banalidad del mal?... 
de las llamativas expresiones de la presencia del mal y de la culpa como es la paradoja de la convivencia de la hipersensibilidad hacia la culpabilidad ajena y la incapacidad para asumir la pro$\mathrm{pia}^{10}$. Aunque la democracia "es el régimen político en el que la culpa de lo que pasa la tienen los ciudadanos"11 conviven el rechazo a la responsabilidad personal con una búsqueda casi irracional de culpables ${ }^{12}$, por ejemplo, ante las grandes catástrofes, analizadas en base a esquemas semejantes ${ }^{13}$.

- Se separa del campo religioso, rechazando a veces de forma ruda el uso del término 'pecado' por ser un concepto del horizonte religioso.

\section{1.- La pandemia del COVID-19}

El terremoto de Lisboa en el siglo XVIII provocó profundos interrogantes en torno a la realidad del mal y la valía de este mundo que, de repente, parecía no ser el mejor de los posibles. Voltaire cuestionaba a Leibniz. Es posible que la pandemia esté abriendo la puerta a otra etapa en la reflexión en la que van anidando algunas ideas:

- Perviven ciertos ramalazos en el imaginario popular, algunos de raíz religiosa, que vinculan la pandemia con un castigo por el rumbo tomado por la humanidad. Afortunadamente son voces menores.

- La naturaleza ha mostrado que no es tan fácil controlar procesos en gran parte desconocidos, con lo cual la sociedad tecnocrática

${ }^{10}$ Lo señalaba claramente Jordi Vaquer en clave de compromiso ecológico: “¿Cómo podemos ser tan conscientes de que somos responsables por el cambio climático, y permanecer tan reacios a hacer cambios en nuestras vidas?... Tenemos ya en nuestras consciencias los mimbres para cambiar ... nuestras actitudes y políticas climáticas... Teniendo una conciencia social tan elevada de la gravedad del problema, no quedan excusas para no pasar a la acción". VAQUER, JORDI, Españoles: líderes en conciencia y en incoherencia: Diario El País (12 de enero de 2021) 10.

${ }^{11}$ Cfr. Savater, Fernando, Díez: Diario El País (6 de octubre del 2018) https://elpais.com/elpais/2018/10/05/opinion/1538769854_311784.html (febrero del 2021).

${ }^{12}$ Cfr. Pérez-Reverte, Arturo, No hay café, gilipollas: XLSemanal (20 de febrero del 2021) 4.

${ }^{13}$ Cfr. Poisson, Jean-Frédéric, Bioética ¿El hombre contra el Hombre?, Rialp, Madrid 2009, 170. 
que había reducido el mal al error -concepto técnico que se podría superar en un futuro no muy lejano (pos-humano o transhumano)ha quedado herida en sus esperanzas soberbias y aspiraciones fantasiosas, ante el riesgo real de desaparición de la humanidad.

- Se han percibido de un modo agresivo los vínculos que tiene el mal físico con el mal moral, colaborador activo en el anterior, permitiendo profundizar recientes campos de reflexión al menos en cuatro discursos:

- La insistencia en la condición débil de lo humano. La vulnerabilidad ${ }^{14}$ parece ser una expresión que incorpora bien los estragos del mal humanidad y que pide la resignificación de los cuidados en la totalidad del pensamiento ${ }^{15}$.

- El fortalecimiento de la unidad de la humanidad. No es fácil escapar al latigazo del mal, aunque no sea fácilmente explicable. El COVID está mostrando que el mal de uno perjudica a todos, que "la familia humana es una comunidad de origen y destino"16.

- La insinuación fuerte de una 'culpa colectiva'17. Las voces que tratan de extraer consecuencias prescriptivas, señalan la responsabilización y, por tanto, la culpabilización implícita de los pró$\operatorname{ximos}^{18}$.

${ }^{14}$ Cfr. Masía Clavel, Juan, El animal vulnerable. Invitación a una filosofía de lo humano (Libros de texto 21), UPCO, Madrid 1997.

${ }^{15}$ Cfr. Arrieta Frutos, Félix, El nuevo marco de la vulnerabilidad: El Diario Vasco (25 de abril del 2021) 31.

${ }^{16}$ Hay más conciencia de formar parte de una comunidad mundial que navega en una misma barca. Francisco, Carta Humana communitas, al presidente de la Pontificia Academia para la Vida con motivo del 25 aniversario de su fundación, 6 de enero de 2019; ID., Carta encíclica Fratelli tutti, Roma 3 de octubre del 2020, 32.

${ }^{17}$ Con esta expresión se quiere recoger una creciente sensibilidad que denuncia que todos somos responsables por nuestro estilo de vida, de las consecuencias climáticas o sociales que sufre la humanidad sin profundizar en la responsabilidad de cada uno que no desaparece. En ese sentido sería un concepto analógico. Según esta culpabilidad no vale una respuesta ajena a la responsabilidad personal: “...los responsables no son ellos por ofrecerlo, sino tú por adquirirlo". LAPUente, Víctor, Decálogo del buen ciudadano. Cómo ser mejores personas en un mundo narcisista, Península-Atalaya, Barcelona 2021², 38 .

${ }_{18}$ Cfr. CAmps, Victoria, Tiempo de cuidados. Otra forma de estar en el mundo, Arpa, Barcelona 2021. 
- Para pensar las prescripciones generales se ha avivado la necesidad de contrarrestar los efectos del pensamiento utilitarista ${ }^{19}$ cuyos criterios matan ${ }^{20}$.

Se podría pensar que, aunque no se hable del pecado ni de culpa original en sociedades secularizadas, está resonando fuertemente la pregunta del Creador a Caín ¿Dónde está tu hermano? (Gn 4,9), como síntoma de un proceso de ampliación de la base de responsabilización y de culpabilización ante lo que se está viviendo.

\section{2.- Recientes investigaciones neurológicas}

Otro actor que se ha subido al escenario es un saber nuevo especialmente interesante por su potencialidad en el conocimiento del ser humano: la neurociencia.

La ciencia y la técnica han triunfado sobre otros tipos de pensamiento, aunque los métodos científicos tienen sus limitaciones ${ }^{21}$. Sin embargo, uno de los campos estrella de las ciencias experimentales en el futuro -junto con el gran desarrollo de la genómica- es el de las ciencias neurológicas. Estas han aplicado sus metodologías en personas que han provocado mucho mal ${ }^{22}$ y aunque los resultados no han alcanzado certezas ni explicaciones definitivas acerca de la desconexión cerebral, sus aportaciones serán necesarias para complementar el esclarecimiento de la realidad del mal existente en la constitución del ser humano, y para la comprensión más plena de los procesos de culpabilización sociales o religiosos.

${ }^{19}$ La pandemia permite identificar sistemas democráticos que han privilegiado la economía en prejuicio de las personas cuya dignidad no merecía una atención más depurada. Cfr. Gomá Lanzón, JAVIER, Virulencias: Diario ABC (29 de marzo del 2020) 3.

${ }^{20}$ Cfr. Amor Pan, José Ramón, Bioética en tiempos del COVID-19, Vozesnavoz, Lugo 2020,103-104. La injusticia de actuaciones en la atención dada a los mayores institucionalizados en las residencias justificadas por el criterio del bien de la mayoría y la maximización de recursos ha levantado voces para pensar la responsabilidad de otro modo. Creemos intuir esa petición en el documento, PonTIFICIA ACAdEMIA de LA VIDA, La vejez, nuestro futuro. La condición de los ancianos después de la pandemia, Roma 2021.

21 “Ninguna ciencia, por exitosa que sea, aportará verdaderamente una luz clarificadora sobre el misterio del mal. Se trata del enigma absoluto que filósofos y teólogos han intentado resolver en vano". Delumeau, Jean, El cristianismo del futuro. Otear el horizonte ¿Va a desaparecer el cristianismo?, Mensajero, Bilbao 2006, 89.

${ }^{22}$ Cfr. Stone, Michael H., The anatomy of Evil, Prometheus, New York 2017. 
Directamente relacionados con la neurociencia se encuentran los matices ofrecidos por la psicología y la psiquiatría ${ }^{23}$, que continúa preguntándose por el origen del mal, su constitución, y las dinámicas de aumento e intensificación ${ }^{24}$ que llevan a apuntar que la maldad no desaparecerá, siempre ha existido y siempre existirá. Señalan las consecuencias del mal en lo que se refiere a la culpabilidad y su utilidad como indicios de integración del ser humano y termómetro de socialización ${ }^{25}$.

\section{3.- Nuevos documentos magisteriales}

El tercer actor representa la reflexión teológico magisterial contemporánea sobre temáticas que reequilibran el peso de las tradiciones anteriores. Suelen ser cuestiones antropológicas que merecen una nueva aproximación. Se han revisitado a partir de algunos documentos recientes, leídos aquí a modo de apunte:

- El documento de la Pontificia Comisión Bíblica (2020) “¿Qué es el hombre? (Salmo 8, 5) Un itinerario de antropología bíblica” está basado en una antropología relacional que habla de la desobediencia original (comentando Gen $3,1-7)^{26}$ sin limitar la libertad humana a la hora de escoger el camino del bien. Resalta que la Escritura no señala las causas por las que prolifera el mal. Las deducciones ante los hechos consumados y presentados "no desen-

${ }^{23}$ Algunas expresiones de Adolf Tobeña parecen no desestimar las apreciaciones agustinianas sobre el pecado de los niños cuando se refiere a aquellos niños que, desde la más tierna infancia muestran indicios de su 'ser destructivos'. Esta percepción sugiere una propensión original e individual. Cfr. ToBEÑA, AdOLF, Neurología de la maldad, preámbulo.

24 "La psicología social ofrece muchísimas pruebas de que el poder de la situación puede más que el poder de la persona en determinados contextos". ZIMBARDO, PHILIP, El efecto Lucifer. El porqué de la maldad (Contextos 124), Paidós, Barcelona-Buenos AiresMéxico 2008, 17.

25 "Frente a la dificultad de acoger al diferente, la culpa puede ser un mecanismo corrector de los excesos que parece pedir el cuerpo". Cfr. VALCÁRCEL, AMELIA, La memoria y el perdón (Pensamiento Herder), Herder, Barcelona 2010, 73, citando a K. Lorentz.

${ }^{26}$ Pontificia commissione Biblica, Che cosa è l'uomo? (Sal 8, 5) Un itinerario di antropologia biblica, Libreria Editrice Vaticana, Roma 2020², 296-300. Incluso el Creador muestra su asombro en Gen 6, 5-6 ante el mal que continúa después del nuevo inicio tras el diluvio. 
trañan el enigma del mal, no explican por qué las personas no resisten a la tentación" ( $\left.\mathrm{n}^{\circ} 202\right)$ tras el supuesto pecado de Eva $\left(\mathrm{n}^{\circ}\right.$ 204).

- La encíclica Laudato si' (2015) ${ }^{27}$-en la que se lee de nuevo Gen 3,16- denuncia las relaciones de dominio del ser humano $(A L$., 19), o señala la degeneración que el pecado introduce en la sociedad cuando el ser humano se comporta como un tirano con la naturaleza $(A L ., 26)$. El mal se explica con la metáfora de un boomerang que lanzado por el hombre se vuelve contra la misma humanidad.

- La exhortación Amoris laetitia $(2016)^{28}$, puede ser señalada en el sentido que distingue algunas situaciones objetivas de mal de las responsabilidades subjetivas, limitadas por diversas circunstancias (CEC., 2352), detallando consecuencias de los principios planteados anteriormente.

- Fratelli tutti (2020) ${ }^{29}$ recoge indicios de reflexiones anteriores y, aunque no aparece el origen del mal, en el documento se extraen responsabilidades tras considerar la familia humana en su totalidad, inmersa en un entorno como el actual caracterizado por la convivencia y el diálogo entre religiones.

Estos documentos, al indagar sobre el origen del mal y del pecado en el mundo, señalan elementos de tradiciones no cristianas ${ }^{30}$, refuerzan las dimensiones relacionales del mal, la responsabilidad subjetiva en situaciones de maldad objetiva y complejidad excepcional, incluyen las perspectivas de las víctimas, señalan instituciones que lo potencian estructuralmente...

Se ha incluido en la misión salvífica de la Iglesia el espectro del cuidado de la humanidad y del otro, ampliando la fraternidad universal a las

${ }^{27}$ Francisco, Carta encíclica Laudato si’ sobre el cuidado de la casa común, Roma 2015.

${ }^{28}$ Cfr. Francisco, Exhortación apostólica postsinodal Amoris laetitia sobre el amor en la familia, Roma 2016

${ }^{29}$ Cfr. Francisco, Carta encíclica Fratelli tutti sobre la fraternidad y la amistad social, Roma 2020

${ }^{30}$ Cfr. Marcos Martínez, Tomás, La sombra de la culpa. La culpabilidad inconsciente en teología y psicología, Valladolid, Estudio Agustiniano 2008, 181-182. 
generaciones posteriores, y situando la exigencia de cuidar la naturaleza creada en la órbita de la sanación del ser humano.

\section{4.- Breve balance}

Así pues, se puede afirmar en principio que la maldad continúa ejerciendo fascinación social y generando procesos de comprensión y responsabilización.

Hay deseos de racionalización de la culpabilidad en la línea de ampliar el enfoque de la responsabilidad hacia la totalidad de los seres hu$\operatorname{manos}^{31}$. La centralidad de la dignidad de la persona como eje en torno al que gira la reflexión ha provocado coherentemente la acentuación de su responsabilidad en el mal y en su superación ${ }^{32}$.

Se ha sugerido el inicio de una nueva etapa, bajo un nuevo marco de reflexión ${ }^{33}$. En ella, la asunción de culpas y peticiones de perdón institucionales ${ }^{34}$ generadas por los males colectivos quieren ser complementadas con una aproximación de las culpas individuales en la atención y el cuidado al vulnerable sin excepciones ${ }^{35}$.

Esta etapa requiere atención multidisciplinar y multidireccional ${ }^{36}$ para referirse a un mal objetivo y aunar las circunstancias subjetivas para gestionarlo. Por lo cual, aunque no se privilegien las explicaciones religio-

${ }^{31}$ No responsabilizarse por los demás es irracional, y estúpido. Cfr. CoRTINA, AdELA, Gerontofobia: Diario El País (23 de julio del 2020) 11.

32 "Es el reconocimiento recíproco de la dignidad y vulnerabilidad entre los humanos el que exige llevar adelante diálogos encaminados a defender esa dignidad, a protegerlos en tiempo de vulnerabilidad, y a cuidar de los seres vulnerables que no forman parte del mundo humano". CORTINA ORS, AdELA, Ética cosmopolita. Una apuesta por la cordura en tiempos de pandemia (Estado y sociedad), Paidós, Barcelona 2021, 169.

${ }^{33}$ Otro marco sobre la culpa de la humanidad diferente de la de Auschwitz, por la diferencia de las víctimas y de los agresores. No todos los elementos de entonces en relación con la culpabilidad y el mal y el pecado nos sirven hoy. Cfr. Arrieta Frutos, Felix, El nuevo marco de la vulnerabilidad.

${ }^{34}$ Cfr. VAlCÁRCEl, Amelia, La memoria y el perdón, 135-142.

${ }^{35}$ Cfr. CAmps, Victoria, Tiempo de cuidados, 12.

${ }^{36}$ Cfr. Rubio, Miguel, El mal nuestro de cada día: Moralia 22 (1999) 151-172. Por su parte CHOZA, JACINTO, Historia del mal, Madrid, Ediciones UESD, 2021, se aproxima desde la filosofía de la cultura señalando que en la era digital se da otra interpretación con nuevos puntos de vista. 
sas, la teología es convocada a revisitar la responsabilidad humana, ampliando la base del mal al género humano, expresándolo de modo que sea comprensible por todos los ciudadanos.

La teología tiene mucho que decir ${ }^{37}$ en el sentido de que los procesos de culpabilización emergentes enriquecen los impulsos teológicos, para pensar mejor y más profundamente la culpa humana y la presencia del Reino de Dios.

\section{2.- Algunas cuestiones teológicas afectadas}

Así pues, se puede hablar de 'creer después de Lisboa' (Voltaire), o 'vivir después de Auschwitz' (Adorno o Jaspers ${ }^{38}$ ). A la espera de la respuesta y evolución de las aportaciones de los grandes pensadores ¿hablaremos de convivir con el COVID?

No todas las lecturas del bien y el mal aportarán novedades al conocimiento del Evangelio y la Revelación. Hay que identificar aquellas consideraciones que por su peso específico puedan afectar al núcleo de la fe. De modo que no se puede permanecer inmutable y no afirmar que es acertado seguir reflexionando sobre los diversos niveles de la condición de maldad objetiva y subjetiva, identificar las realidades y los nuevos rostros que la expresan y la relación con las deficiencias subjetivas.

Más en concreto, destacar tres cuestiones que afectan a los saberes humanos en general y a la teología y a la antropología en particular, con la novedad de exigir la racionalización a las posiciones no religiosas. Es posible indicar con Habermas que por la persistencia de la religión, el reconocimiento de la contribución positiva de las religiones a la vida social, la necesidad de dar cabida a las opiniones religiosas en la arena pública y mantener la adecuada separación del marco religioso exige el esfuerzo de

37 "The Corona Crisis as a Challenge for Theology and Church", es el tema central de un número de ET Studies. Journal of the European Society for Catholic Theology 12/1 (2021) 3-127

${ }^{38}$ Acudir a Auschwitz en el horizonte de confrontación entre la omnipotencia de Dios y el mal se ha convertido en una especie de imperativo filosófico-teológico de las últimas décadas. Cfr. JASPERS, KARL, El problema de la culpa. Sobre la responsabilidad política de Alemania (Pensamiento contemporáneo 52), Paidós, Barcelona 1988. JonAs, Hans, El concepto de Dios después de Auschwitz. Una voz judía, en: ID., Pensar sobre Dios y otros ensayos, Herder, Barcelona 1998, 195-212. 
responder a las dudas que generan las justificaciones secularizadas para eliminar la injusta asimetría que pesa sobre los ciudadanos religiosos en las instituciones democráticas seculares. La sociedad postsecular ha asumido la exigencia de un proceso de aprendizaje recíproco e integrador de la mentalidad religiosa como la razón secular ${ }^{39}$. Del mismo modo que no es culturalmente habitable una respuesta teológica ingenua, aislada del conjunto del mensaje cristiano ${ }^{40}$ que dé satisfacción de un Dios ajeno a los conflictos existenciales ${ }^{41}$, tampoco son válidas las afirmaciones interesadas de un Dios canalla que parece permitir el mal, y que nos debería una explicación ${ }^{42}$.

\section{1.- La comprensión de la realidad en su totalidad}

En la búsqueda del significado más profundo de la realidad ${ }^{43}$ que afecta a lo propiamente teológico inevitablemente surge la pregunta por la esencia y el génesis del mal. Siendo fieles a los anhelos de verdad amarrados a la comprensión del mundo no se puede esconder la presencia de un lado oscuro. En la autenticidad del planteamiento y de las tentativas de respuesta se reconoce uno de los termómetros que indica la temperatura de la credibilidad de las teorías que se planteen. Muchas explicaciones fracasan precisamente aquí, en el dar razón de la convivencia y mixtura de la Ciudad de Dios con la de los hombres, del bien y del mal, del egoísmo y de la caridad.

${ }^{39}$ Cfr. Ferrara, Alessandro, El horizonte democrático. El hiperpluralismo y la renovación del liberalismo político (Pensamiento Herder), Herder, Barcelona, 2014, 75. Cfr. HABERMAS, JÜRgEN, La religión en la esfera pública, en: ID., Entre naturalismo y religión, Paidós, Barcelona 2006, 121-155.

${ }^{40}$ Las diversas maneras de comprensión del mensaje de la cruz de Cristo, el sacrificio expiatorio, el rescate, la satisfacción vicaria quedan superadas por la recapitulación amorosa. Cfr. Marcos Martínez, Tomás, La sombra de la culpa, 201.

${ }^{41}$ Cfr. Gelabert, MARTín, El mal como estigma teológico. ¿Un signo de interrogación en el discurso sobre Dios?: Moralia 22 (1999) 191-222.

${ }^{42}$ Cfr. Ruiz de la PeÑa, Juan L., Teología de la creación (Presencia teológica), Sal Terrae, Santander $1987^{2}, 157$ ss.

${ }^{43}$ Cfr. Hieke, Thomas, Theology and the COVID-19 Pandemic. Does Theology Provide Answers to the Coronavirus Pandemic?: ET Studies. Journal of the European Society for Catholic Theology 12/1 (2021) 5-16. 
Todo espíritu que aborde las cuitas de la humanidad debe asumir el enigma del mal incluyendo sus aspectos estructurales. Hay que contar con la experiencia de nacer en un mundo donde hay mal, con una existencia bajo el riesgo de colaborar inconscientemente con él-camuflado tras múltiples rostros de difícil identificación ${ }^{44}-$, y con la posibilidad de sostener estructuras que lo favorecen ${ }^{45}$.

La sanación del mal está en el centro de las religiones en su intento de decir qué es, salvando a Dios de sus causas y efectos y ayudando al ser humano a vivir con él y superarlo. La fe habría sido colonizada por ese gran misterio, que no podía ser explicado por los conocimientos racionales. Dentro del fenómeno religioso el mal no tiene la última palabra ${ }^{46}$.

Pero en las actuales sociedades plurales, que han cambiado los altares religiosos por el del secularismo, el punto de partida más adecuado, el lugar justo para explicar del origen del mal, es el que apunta hacia el respeto de la autonomía de las realidades humanas, que, respondiendo a leyes propias, introduce negatividad y provoca víctimas.

Lógicamente las religiones no pueden renunciar a seguir comprendiendo la relación de Dios con sus criaturas. Dicha cuestión quedaría desplazada al aceptar que técnicamente se puede explicar un mundo sin Dios. El mal y su origen no serían un problema del ámbito religioso, sino filosófico. Tendría que ver con las limitaciones sobrevenidas con la realidad material, por la fiabilidad de la materia prima.

El reto en la comprensión del mal más que buscar soluciones (frente a maniqueísmos y gnosticismos) implica respuestas auténticas que integren la reflexión teológica y la filosófica ${ }^{47}$.

${ }^{44}$ Cfr. Bauman, Zygmunt - Donskins, Leonidas, Maldad líquida. Vivir sin alternativas (Estado y sociedad) Paidós, Barcelona 2019.

45 "Los principales problemas a los que se enfrenta hoy la humanidad tienen el carácter de problemas planteados por un sistema interdependiente y concatenado ante los cuales son ciegos sus componentes individuales: insostenibilidad, riesgos financieros y, en general, aquellos que están provocados por una larga cadena de comportamientos individuales que pueden no ser en sí mismos malos, pero sí lo es su desordenada agregación”. INNERARITY, DANIEL, Sobrevivir a los malos gobernantes: Diario El País (4 de enero de 2017) http://elpais.com/elpais/2016/12/28/opinion/1482948155_120317.html (enero del 2017)

${ }^{46}$ Cfr. Neusch, MARCEL, El enigma del mal (Presencia teológica 176), Sal Terrae, Maliaño 2010, 9.

${ }^{47}$ Ricoeur, PAul, Il male: una sfida alla filosofia e alla teologia (Il pellicano rosso 22), Morcelliana, Brescia $2005^{4}$. 
Tras enfocar la cuestión, una primera tarea es la tarea crítica denunciadora de los extremos en los planteamientos y los excesos inaceptables en las respuestas.

Comenzando por los excesos racionales, parece que el mero abordaje teórico de la razón técnica no supera el problema ${ }^{48}$. No salva ni a Dios, ni al individuo. A Dios por sus excesos racionales al aproximarse a la trascendencia inalcanzable e ilimitada. Al ser humano porque puede ser sacrificado en beneficio de la totalidad por leyes todavía incomprensibles.

Igualmente, la respuesta estética ${ }^{49}$ tampoco es suficiente, pues corre riesgos semejantes al sacrificar al individuo sufriente en beneficio de la universalidad ${ }^{50}$. En ese sentido, la razón práctica parece haber hecho un juicio sumarísimo a la razón pura que inconscientemente ha alimentado la desesperanza, la violencia, la connivencia con él.

Continuando por los excesos a señalar, igualmente hay que ser críticos dando por superadas las propuestas religiosas acompañadas de fideísmos mistéricos y espiritualismos míticos, a menudo conjugadas con dinámicas expiatorias que no responden suficientemente a la victimización injusta ni a la pregunta:-¿Por qué a mí?

Una segunda tarea articula el discurso partiendo de las sinergias de la fe y la razón: "la fe ayuda a la ciencia a abrirse a la realidad en toda su plenitud y profundidad, sin robarle nada de protagonismo ni de cientifici-

${ }^{48}$ La finitud sería la explicación teórica para el mal cuyas consecuencias en lo que dice respecto al ser humano serían la labilidad, la 'no adecuación' del hombre consigo mismo, la 'desproporción' entre la finitud y la infinitud. Tendría que ver más con las limitaciones ínsitas en la condición humana: "Lo que puede fallar, alguna vez falla”, dirá SANTO TomÁs, Suma contra Gentiles, III, 71. Ricoeur ofrece puntos de diálogo con la teología para actualizar la reflexión sobre el origen del mal desde la 'labilidad', que estaría apoyada en la 'limitación'. Cfr. Ricoeur, PAul, Finitud y culpabilidad (Estructura y procesos), Trotta, Madrid 2004.

${ }^{49}$ El mal se convierte en un concepto relacional, que se entiende en conexión con el bien en cuanto carencia de bien. "El mal no es sustancia ninguna, porque si fuera sustancia sería un bien"; "el mal no tiene naturaleza alguna, sino que la pérdida del ser tomó el nombre de mal"; "ninguna naturaleza, absolutamente hablando, es un mal. Este nombre no se da más que a la privación de bien". SAN Agustín, Confesiones VII, 12,18; La Ciudad de Dios XI, 9 y 22.

${ }^{50}$ El mismo Agustín identifica en sus Confesiones algunos interrogantes que permanecen. Cfr. San Agustín, Conf., VII, 3, 5. 
dad"51. Aquí entraría el pensar a Dios ${ }^{52}$ conviviendo con el mal, cuestión que resaltada por Epicuro ${ }^{53}$ sigue siendo la pregunta esencial de la teodicea ${ }^{54}$.

Aplicar el zoom de la filosofía y la teología, de la razón y la fe, purificadas de sus excesos permite investigar y conocer las leyes de la realidad física sin limitaciones, con una mayor profundidad y generar empeños para corregir sus efectos negativos, diseccionando con precisión la tarea y las responsabilidades humanas. Se le recuerda a la ciencia experimental la dimensión mistérica de la realidad no completamente desmitificada.

Por parte de la teología, cuando se asume el diálogo inicial con concepciones que desestiman la responsabilidad divina en el origen del pecado, se libera de lastres pesados en el cuestionamiento de la figura de Dios como realidad última, e incorpora nuevas perspectivas que asumen la convivencia enigmática del bien y el $\mathrm{mal}^{55}$. Es posible seguir reflexionando y replantear la relación hombre/Dios ${ }^{56}$ y sus mediaciones, dentro de la dinámica procesal en expansión que no coarta los deseos de superar el mal y alcanzar una justicia plena (Mt 25).

51 "La mirada de la ciencia se beneficia así de la fe: esta invita al científico a estar abierto a la realidad, en toda su riqueza inagotable. La fe despierta el sentido crítico, en cuanto que no permite que la investigación se conforme con sus fórmulas y la ayuda a darse cuenta de que la naturaleza no se reduce a ellas. Invitando a maravillarse ante el misterio de la creación, la fe ensancha los horizontes de la razón para iluminar mejor el mundo que se presenta a los estudios de la ciencia". FrancisCO, Carta encíclica Lumen fidei, Ciudad del Vaticano, 29 junio 2013, 34.

${ }^{52}$ La pregunta desde la teología sería ¿por qué -sabiendo que sería limitado e imperfecto por finito y libre y por tanto abierto a la realidad del mal- Dios crea un mundo así? Schillebeeckx ha plasmado los términos del planteamiento aporético en esta aplicación concreta: "Para nuestra experiencia de hombres de la segunda mitad del siglo XX, esta omnipotencia ya no es algo tan obvio. ¿No habla contra esa omnipotencia la historia entera de la humanidad? ¿acaso Auschwitz -como símbolo de tanto mal satánico en nuestra historiano habla contra esa omnipotencia? ¿o todo el dolor inocente y la injusticia de este mundo, o el sufrimiento del tercer mundo? Considerémoslo a una escala menor: ¿no contradice ya la omnipotencia de Dios la muerte de un solo niño inocente?’. SCHILlEBEECKX, EDWARD, Los hombres, relato de Dios (Verdad e imagen), Sígueme, Salamanca 1994, 143.

${ }^{53} \mathrm{El}$ texto de Epicuro es recogido por Lactancio, De ira Dei, 13,20-21.

${ }^{54}$ Cfr. Kreiner, Armin, Dios en el sufrimiento. Sobre la solidez de los argumentos de la teodicea, Herder, Barcelona 2007.

${ }^{55}$ Expresada en clave narrativa por la parábola evangélica del trigo y la cizaña (Mt 13, 24-30) recuerda la convivencia y confusión del bien y del mal y la dificultad de distinguirlos alimentando de ese modo una dinámica tensional para superarlo.

${ }^{56}$ La vivencia del mal ayuda a purificar la imagen de Dios que erróneamente se puede formar. Cfr. GElABERT, MARTín, El mal como estigma teológico, 191-222. 
Pensar el mal desde sí mismo sin buscar responsables externos que hipotequen la libertad humana permite a la teología actualizar la oferta de sentido del cristianismo en una propuesta que no ignore ningún aspecto de la realidad y perfeccione soluciones pretendidamente cerradas y definitivas.

\section{2.- La aproximación a la persona en su unidad y profundidad}

En lo que afecta a lo propiamente antropológico, las consideraciones tienen que ver con la responsabilidad humana, respondiendo primordialmente a un cuestionamiento más básico que ilumina el ser criatural, la finitud, la limitación, la contingencia o la vulnerabilidad que provocan mal y sufrimiento que constituye al género humano ${ }^{57}$.

A este respecto es clásico el texto de los Hermanos Karamazov para indicar que nadie escapa a la realidad del mal ${ }^{58}$. Importa la caracterización que señala la presencia en el corazón humano que no desea hacer el mal pero que no puede evitarlo, como si fuera víctima y culpable al mismo tiempo, producto de un engaño, esclavo en una prisión, que en su acción hace daño a otros provocando víctimas que claman:-¿Por qué a mí?

Las ciencias humanas ofrecen constantemente datos novedosos sobre las propias contradicciones, y en su evolución en el conocimiento de la conciencia y de los elementos afectivos de la persona se constituyen en una irrenunciable clave de lectura del fenómeno de la culpabilidad humana $^{59}$ amarrado con el ancla del riesgo de la desintegración ${ }^{60}$. Las variadas perspectivas complementarias que aportan las ciencias sirven para puntualizar los sentimientos de culpa del ser humano situado en un

${ }^{57}$ Cfr. Cortina Ors, Adela, Ética cosmopolita, 28-30.

58 "Todos los hombres llevan un demonio en su interior, hijo de un carácter colérico, del sadismo, de un desencadenamiento de pasiones innobles, de enfermedades contraídas en un régimen de libertinaje, de la gota, del mal funcionamiento del hígado...". DosTOIEvsKI, FIODOR, Los hermanos Karamazov.

${ }^{59}$ Seguirán aportando beneficios para la comprensión de la experiencia religiosa de los ciudadanos, las trazas de la presencia y la gracia de Dios en la vida humana. Cfr. RuBio, Miguel, Significación del fenómeno de la culpa. La perspectiva teológico-ética: Moralia 8 (1986) 99-124.

${ }^{60}$ La integración de la persona define la culpa y su vivencia. En sentido positivo, muchas de las motivaciones de los voluntarios tienen componente de autosatisfacción para corregir la culpabilidad emotiva del individualismo de los individuos especialmente los más jóvenes. Lo señala BÉJAR, HelEnA, El mal samaritano. El altruismo en tiempos de escepticismo, Anagrama, Barcelona 2001. 
mundo secularizado ${ }^{61}$, y relacionarlas con la dimensión objetiva de los contravalores que origina el mal comportamiento ${ }^{62}$. De ese modo muestran el universo de valores y dan seguridad a la praxis humana, introduciendo a la persona en la realidad ${ }^{63}$.

Estas contribuciones afectan al espacio de la reflexión teológica que debe continuar adaptándose y acompañando el proceso de individuación como hizo en el pasado junto a las novedades humanizadoras del mundo bíblico y griego. En esta dinámica, no es de extrañar que el discurso sobre Dios y sobre el hombre haya evolucionado hacia una antropología relacional $^{64}$ incorporando la mejora de la comprensión de la responsabilidad ${ }^{65}$, incluyendo a las generaciones futuras y el entorno ecológico.

Quedan, no obstante, muchas tareas pendientes en esta cuestión de comprender a la persona en su totalidad. Aquí se sitúan la percepción y estimativa del mal ${ }^{66}$, continuar la renovación de la antropología bíblica y

${ }^{61}$ A veces hacen la función de contraste o crítica. Cfr. El mal hoy y el proceso de humanización: Concilium 329 (2009) Número monográfico.

${ }^{62}$ Que dificulta la realización de la persona y la de todo el género humano. Cfr. BousQUET, FRANÇOIS, Interpretaciones del mal en las religiones y las culturas: Selecciones de teología 172 (2004) 290-304.

${ }^{63}$ Realiza la función de recuerdo del pasado y advertencia para el futuro, frente a la razón cínica. "La culpabilidad constituye una estructura básica para la integración del sujeto y para su acceso a la realidad y al mundo de los valores". Domínguez MoRANO, CARLOS, Creer después de Freud (Biblioteca de teología 18), San Pablo, Madrid 2002, 147.

${ }^{64}$ Señala la culpabilidad como una ruptura con repercusiones interiores que se actualizan libremente en las decisiones más allá de un origen en el sentido temporal. Cfr. GELABERT BAllester, Martín, La astuta serpiente. Origen y transmisión del pecado, Verbo Divino, Estella 2008, 118.

${ }^{65}$ Identificando etapas de culpabilidad. Cfr. Burón OREJAS, JAVIER, Psicología y conciencia moral (Proyecto 113), Sal Terrae, Santander 2010, 92-107, que presenta un intento de estructuración de la culpabilidad en nueve niveles distribuidos en esas tres dimensiones heterónoma, autónoma y teónoma.

${ }^{66}$ En el caso de la culpabilidad, realidad compleja que ha recibido atención desde diversos puntos de vista, es complicado sostener fácilmente las repetidas afirmaciones de Pío XII en el Mensaje del Congreso Catequético de Boston (1946): "Es posible que el mayor pecado en el mundo de hoy consista en que los hombres han empezado a perder el sentido del pecado". Cfr. PIO XII, Radio Message to Participants in the National Catechetical Congress of the United States in Boston, Castel Gandolfo, 26 October 1946 http://w2.vatican.va /content/pius-xii/en/speeches/1946/documents/hf_p-xii_spe_19461026_congresso-catechistico-naz.html (marzo del 2021). 
su relación con otros aspectos decisivos del cristianismo como la escato$\operatorname{logí}^{67}$, la praxis sacramental ${ }^{68}$ o la moral ${ }^{69}$. En el momento que el mal genera un conflicto de la culpa subjetiva junto a las normas objetivas, el discernimiento tiene que echar mano de la misericordia y la compasión tras la identificación de lo denominado 'intrínsecamente malo'.

\section{3.- La rebelión ante el mal: caminos de superación}

La razón práctica es consciente de que no se trata solamente de ser fotógrafos de la realidad en su totalidad (habilitando el discurso sobre la bondad de Dios y la convivencia con el mal) o del abismo del corazón y del cerebro humanos. Impulsa a hacerse cargo de la vida y anhelos de los seres humanos que viven con la esperanza de superar el mal. Es más razonable, más vital y consubstancial al ser humano la vacuna de la esperanza. La pregunta es: ¿qué se puede hacer contra él?

La respuesta a dicha cuestión sorprende al pasar de la penuria para justificar la solidaridad en el mal a la amplia solidaridad hacia el bien en un mundo inacabado. Se comparten múltiples iniciativas para conjurar el riesgo de las desmoralizaciones sociales y alcanzar una integración humanizante $^{70}$, en lo que Beorlegui denomina "urdimbre solidaria y responsable" ${ }^{\text {71 }}$.

${ }^{67} \mathrm{Si}$ la fe llama a la gracia, la revelación lo hace con la esperanza. MARCOS MARTínEZ, TOMÁs, La sombra de la culpa, 219.

${ }^{68}$ Cfr. Gómez Mier, Vicente, Adiós al confesionario, Nueva utopía, Madrid 2000.

${ }^{69}$ Falta una jerarquía de verdades evangélicas para definir más claramente la teología del pecado en virtud de la relación con el centro de la fe o de otros criterios evangélicos responsabilizando a cada uno en su nivel de posibilidades y capacidades. Señalado ya en Populorum progressio. Cfr. CAMACho LARAÑA, Ildefonso, La aportación eclesial de Populorum progressio a Laudato Si'. Desarrollo humano integral y ecología integral, en: Larrú, Jose María (Coord.), Desarrollo humano integral y Agenda 2030. Aportaciones del pensamiento social cristiano a los Objetivos de Desarrollo Sostenible (BAC. Estudios y ensayos, Filosofía y ciencias), BAC, Madrid 2020, 120.

${ }^{70}$ Se han privilegiado los criterios discursivos que aúnan las fuerzas de la reflexión, trabajando para superar los desequilibrios que deshumanizan. Zimbardo analiza algunos de los procedimientos que usa el mal, la desindividuación, la obediencia a la autoridad, la pasividad frente a amenazas, la autojustificación o la racionalización para desenmascarar la deshumanización que los acompaña. Cfr. Zimbardo, Philip, El efecto Lucifer, 17.

${ }^{71}$ Cfr. Beorlegui, Carlos, Antropología filosófica. Nosotros: urdimbre solidaria y responsable (Filosofía 28), UD, Bilbao $2009^{3}$. 
En esta solidaridad frente al mal, la teología ensancha el espacio de su tienda al escuchar respuestas y críticas de voces no religiosas, purificando sus explicaciones, conociendo sus límites y revisándolos ${ }^{72}$, sanando relaciones y purificando sentimientos ${ }^{73}$. Mejora gracias a la vía de la praxis cuando asume y prioriza la perspectiva de las víctimas de la injusticia. La solidaridad $^{74}$, la escucha "del clamor de quienes sufren violencia y se ven oprimidos por sistemas y mecanismos injustos" 75 incorporan nuevos perfiles para pensar la culpabilidad y la reparación, la reconciliación justa.

Lo cual no significa perder su objetivo propio. Al contrario, al ponerse en el lugar del que sufre ("si indus esset" ") aplica en la práctica la misericordia divina y asume la 'ontología de la persona' situando la libertad en la esperanza de la comunión infinita más allá del tiempo y del espacio, junto al Dios con-sufriente y la vida entregada por Jesús de Nazaret.

\section{3.- A modo de conclusión}

Le corresponde a la teología -como interpretación del hombre y de su época-, seguir haciendo su trabajo de acompañar la evolución de las ideas y el desarrollo del espíritu humano a la par de la reflexión más racional en busca de "la verdad de lo esencial y lo esencial de la verdad"77.

${ }^{72}$ Desde una relectura de la antropología bíblica que lleva a pensar el pecado original en su contexto adecuado excluyendo una visión infantilizadora del ser humano (CIC., 2657). Cfr. Torres QueIruga, Andrés, Repensar el mal. De la ponerología a la teodicea (Estructuras y procesos. Serie religión), Trotta, Madrid 2012, 37-39.

${ }^{73}$ Esta intuición responde a los anhelos de la teología después del Vaticano II. Cfr. Gelabert BAllester, MARTín, La astuta serpiente, 118.

${ }^{74}$ Cfr. Metz, Johann-Baptist (dir.), El clamor de la tierra. El problema dramático de la teodicea, Verbo Divino, Estella 1996; Gutiérrez, Gustavo, Hablar de Dios desde el sufrimiento del inocente: reflexión sobre el libro de Job, Sígueme, Salamanca 20217\% Sobrino, Jon, La fe en Jesucristo. Ensayo desde las víctimas, Trotta, Madrid 1999.

${ }^{75}$ SínOdo DE LOS OBISPOS, La justicia en el mundo. Nuevas responsabilidades de la Iglesia en el campo de la justicia, Roma 1971, Introducción.

${ }^{76}$ Crítica que le hace Bartolomé de las Casas al teólogo Juan Mayor cuando justifica sin empatía ninguna la moralidad de la conquista de los pueblos de Latinoamérica. Cfr. BARTOlomé de las CASAs, Apología o declaración y defensa universal de los derechos del hombre y de los pueblos, C. 53, p. 330.

77 Cfr. Cordovilla, Ángel, Teología en tiempos de pandemia: "Ahora es tiempo favorable, ahora es día de salvación (2 Cor 6, 2)": Revista Vida Nueva 3178 (16-22 de mayo de 2020) Pliego. 
Ese quehacer incluye cuestiones conflictivas como la desafiante tarea de dar respuestas del mal compartido por toda la humanidad. Es una responsabilidad que no ha desaparecido, ni mucho menos, del horizonte del pensamiento ${ }^{78}$. Lo cual permite afirmar que:

- El teólogo que se debruza sobre el tema del pecado (original o no) y de la culpabilidad no está desenfocado en sus preocupaciones.

- Existe un margen para revisitar la cuestión desde la plataforma propia de las ciencias teológicas y hacerlo con dignidad caminando junto con otros estudios hacia un corpus doctrinal integral que no decapite el acceso a la trascendencia.

- No será fácil incorporar los datos de las ciencias humanas y experimentales a la teología ${ }^{79}$. El marco situacional es tan complejo que incluso es valorado negativamente por algunos autores que sostienen que no ha habido grandes avances en la reflexión contemporánea ${ }^{80}$.

Así las cosas, y para concluir, se podría apuntar que uno de los servicios que la teología hace a la Iglesia es provocar y facilitar el diálogo con el discurso secular ${ }^{81}$. Aunque no siempre la presencia del concepto culpabilizador sea patente, sin embargo, se desliza silenciosamente entre los textos, de tal modo que la teología -al hacerlo explícito- proporciona el justo abordaje de la maldad y la culpabilización ${ }^{82}$ completando la investigación de las ciencias afines.

${ }^{78}$ Cfr. Rodríguez Cuartango, Pedro, El terremoto de Lisboa: Diario ABC (22 de noviembre de 2019) 15 .

${ }^{79}$ Así constatamos, por ejemplo, en el sugerente estudio -ya citado- del profesor Tomás Marcos que en diálogo con la psicología explica cómo la realidad del pecado original, del mal original, está bajo sospecha de existir. Cfr. MARCos MARTínez, Tomás, La sombra de la culpa. La culpabilidad inconsciente en teología y psicología, Estudio Agustiniano, Valladolid 2008.

${ }^{80}$ Cfr. Neusch, Marcel, El enigma del mal (Presencia teológica 176), Sal Terrae, Maliaño 2010, 105-106.

81 “... by serving the world, by opening up the so-called secular, theology is doing a substantial service to the Church". Prüller-JAGENTEUfel, GUNTER - KRUIP, GeRHARD, "European theology" (editorial): ET Studies. Journal of the European Society for Catholic Theology 11/1 (2020) iv.

${ }^{82}$ Cfr. Bruckner, Pascal, La tiranía de la penitencia. Ensayo sobre el masoquismo occidental, Ariel, Barcelona 2008. Ante una cierta tiranía de la penitencia de la denuncia y 
En este momento los estudios de neurociencia/neuroética están abriendo un campo de investigaciones excepcional para el desarrollo de la respuesta al mal y de la culpa. Alejarlos totalmente de la reflexión teológica acerca de la revelación sobre lo humano no parece una estrategia adecuada. La teología puede ser un apoyo para corregir desenfoques de laicas concepciones de ingenua fe en un ser humano ideal despojado de su dimensión mistérica. Un humanismo verdadero no puede obviar la reflexión sobre los deseos de plenitud de cada individuo y debe pensar la justicia junto con la verdad al dar explicaciones de las causas intrahistóricas del mal, del dolor y de la injusticia ${ }^{83}$.

Las elaboraciones teológicas realizadas desde las víctimas de la injusticia y del pecado -cuya figura podría ser el justo sufriente de Jobpiden continuidad ${ }^{84}$. La invitación conciliar para hacer una reflexión «a la luz del Evangelio y de la experiencia humana» (GS., 46), se cumple adecuadamente si incorpora la experiencia del mal y del dolor que genera en las víctimas. Esta vía se apropia de la contradicción entre el mal generado y el mal sufrido, individual o colectivamente, y aproxima a la racionalidad de los procesos vitales, narrados de forma figurada y trágica en el libro del Génesis, superándolos desde la clave evangélica de Jesús de Nazaret que cura y perdona ${ }^{85}$. Abundar en este camino perfecciona la comprensión del Dios misericordioso que sale al encuentro de la criatura humana, solidaria y colaboradora en el mal, y permite comprender mejor la justificación y la salvación de Jesucristo, que "pasó haciendo el bien y curando a todos los oprimidos por el mal" (Hch 10,38).

\footnotetext{
de la indignación hipersensibilizada, la sabiduría teológica permite equilibrar solicitudes de justicia vindicativa, tanto ante los excesos de las élites controladoras de poder, o de las exageraciones de asambleas exaltadas. El secularismo ha recibido la enseñanza del pecado original extrapolándola hasta límites exagerados ante la falta del tope de la redención que modula la experiencia del mal con la misericordia divina.

${ }^{83}$ Para lo cual es válido incorporar estas novedosas investigaciones, del mismo modo que se situaron adecuadamente las sospechas del marxismo o del psicoanálisis. Cfr. GoNZÁlez de CARDEDAl, Olegario, La teología en España (1959-2009) Memoria y prospectiva (Ensayos 431), Encuentro, Madrid 2010, 226.

${ }^{84}$ Teología desde las víctimas (Diáspora), Tirant humanidades, Valencia 2017.

${ }^{85}$ Cfr. Vitoria, Francisco Javier, En las víctimas está Dios reconciliando el mundo (Cristianisme i justicia Virtual 17), Barcelona 2020.
} 